\title{
Echocardiography in stroke and transient ischaemic attack
}

\author{
John B Chambers, Mark A de Belder, David Moore
}

\begin{abstract}
Stroke and transient ischaemic attack (TIA) remain controversial indications for echocardiography. In some centres they represent $40-50 \%$ of the total requests for transoesophageal studies, while many stroke units never request echocardiography as a matter of routine. We need to examine the reasons for these wide differences in practice.
\end{abstract}

\section{How is cardiac stroke diagnosed?}

Approximately $20 \%$ of strokes are caused by cerebral haemorrhage and $80 \%$ by infarction. ${ }^{1}$ Of the infarctions, a proportion are thrombotic and the rest as a result of emboli either from artery to artery within the cerebral circulation or from the heart or aorta. The diagnosis of a cardiac source for emboli is based to some degree on the clinical presentation and the results of computed tomography or magnetic resonance imaging (table 1 ), ${ }^{2}$ but largely on the findings on echocardiography itself. This has introduced a bias that has tended to overstate the importance of echocardiography particularly via the transoesophageal approach. Thus, studies based on transthoracic echocardiography have suggested that approximately $15 \%$ of TIAs and $15-35 \%$ of cerebral infarcts are cardiac in origin ${ }^{3}$ while transoesophageal studies suggest figures of at least $50 \%$ and up to $83 \%$. ${ }^{4}$ Some echocardiographic abnormalities, however, are controversial or even spurious causes of stroke - for example, mitral prolapse, atrial septal aneurysm or mitral annular calcification. The role of echocardiography in

Table 1 Clinical findings suggesting embolic stroke

- Abrupt onset

- Previous infarction in other cerebral territories

- Associated peripheral emboli

- Cortical, large subcortical $(>1.5 \mathrm{~cm}$ ) or multiple lesions on computed tomography or magnetic resonance imaging

Table 2 The role of echocardiography in patients with stroke

- Detecting a direct source of emboli, eg, thrombus, myxoma, vegetation

- Detecting a condition with a known risk of stroke, eg, mitral stenosis, dilated left ventricle

- Refining the risk in a condition known to be associated with emboli, eg, atrial fibrillation

Table 3 The annual risk of stroke in relation to left atrial size and left ventricular function

\begin{tabular}{lc}
\hline Findings & Annual risk (\%) \\
\hline Atrial fibrillation + normal echocardiogram & 1.5 \\
Atrial fibrillation + left atrium $>2.5 \mathrm{~cm} / \mathrm{m}^{2}$ & $8 \cdot 8$ \\
Atrial fibrillation + global left ventricular dysfunction & 12.6 \\
$\begin{array}{l}\text { Atrial fibrillation + left atrium }>2.5 \mathrm{~cm} / \mathrm{m}^{2} \text { and } \\
\text { moderate left ventricular dysfunction }\end{array}$ & 20.00 \\
\hline
\end{tabular}

Left atrial area was used; this is not a widely applied measure but is intuitively sensible. Data from reference 15 . patients suspected of suffering a cardiac embolus must therefore be examined critically.

\section{Role of echocardiography in patients with} stroke

Echocardiography may find a direct source of emboli-for example, thrombus, myxoma or vegetation (table 2 ). Up to $1 \%$ of all strokes in patients aged under 50 years may be caused by a left atrial myxoma ${ }^{5}$ and up to $15 \%$ of patients with endocarditis present with an embolic event. ${ }^{6}$ However, more usually, echocardiography identifies a condition with a known risk of emboli-for example, mitral stenosis may be the underlying cause of cerebral infarction even if a thrombus cannot be imaged. The thrombus might be beyond the resolution of the technique or might already have embolised. Another example is dilated cardiomyopathy where the risk of stroke is $5 \%$ per year regardless of whether left ventricular thrombus is identified on echocardiography.

\section{When should transthoracic}

\section{echocardiography be requested?}

In the absence of a significant abnormality on clinical cardiovascular examination or on the electrocardiogram, the yield from transthoracic echocardiography is virtually zero and it should not be performed routinely..$^{8-12}$ However, in young subjects (younger than 50 ), transthoracic examination is usually done as the immediate prelude to transoesophageal echocardiography. Some authors have suggested that the transthoracic study can guide the use of transoesophageal echocardiography. Thus, in two studies the presence of $92 \%^{13}$ and $95 \%^{14}$ of abnormalities on transoesophageal examination were predicted by transthoracic abnormalities such as left atrial enlargement, left ventricular hypertrophy or mitral valve thickening. These studies suggested that transoesophageal echocardiography was not necessary in patients aged under 40 years with a normal transthoracic study. However, at least anecdotally, there is still a small yield of unsuspected vegetations or thrombi on transoesophageal examination.

It could be argued that if a significant clinical abnormality such as atrial fibrillation or mitral stenosis is found, echocardiography is no longer necessary. However, echocardiography will still refine the risk of embolisation. For example, in a patient in atrial fibrillation the risk of stroke is low if the echocardiogram is completely normal, but progressively higher if 
the left atrium is dilated and the left ventricle hypokinetic (table 3$).{ }^{15}$ In a patient with mitral stenosis, echocardiography may reveal a ball thrombus for which the management becomes urgent surgery rather than simply anticoagulation.

Atrial fibrillation is a marker for stroke rather than necessarily the direct cause. It is associated with other conditions such as hypertension or heart failure, which themselves carry an independent risk of stroke. For this reason atrial fibrillation is found in $11 \%$ of patients suffering cerebral haemorrhage as well as $25-35 \%$ of those with cerebral thrombosis. These figures are lower than the incidence of $60 \%$ in patients with embolism, ${ }^{4516}$ but they still underline that brain imaging to exclude haemorrhage should always be performed in patients in atrial fibrillation before starting anticoagulation.

\section{How important is transoesophageal echocardiography?}

In contrast to transthoracic echocardiography, the transoesophageal approach frequently shows abnormalities even in the absence of clinical signs (table 4). These include patent foramen ovale, atrial septal aneurysm, left atrial spontaneous contrast, left atrial thrombus, and aortic atheroma. However, the importance of many of these findings is difficult to evaluate because of a lack of standardisation of definitions and a relative lack of control comparisons.

\section{PATENT FORAMEN OVALE}

Some authors consider a patent foramen ovale present if five or more microcavitations are seen within three cycles, ${ }^{17}$ some if only three are seen, ${ }^{13}$ and some only two ${ }^{18}$ or even one. ${ }^{1419}$ There is some evidence that the number of microcavitations is approximately related to the anatomical size of the patent foramen ovale. $^{19}$ A reasonable arbitrary grading is between one and five (small), five to 20 (moderate), and more than 20 (large). Most authors make between three and six injections and most use a Valsalva manoeuvre that increases the yield of patent foramen ovale by at least

Table 4 Possible causes of stroke found on echocardiography

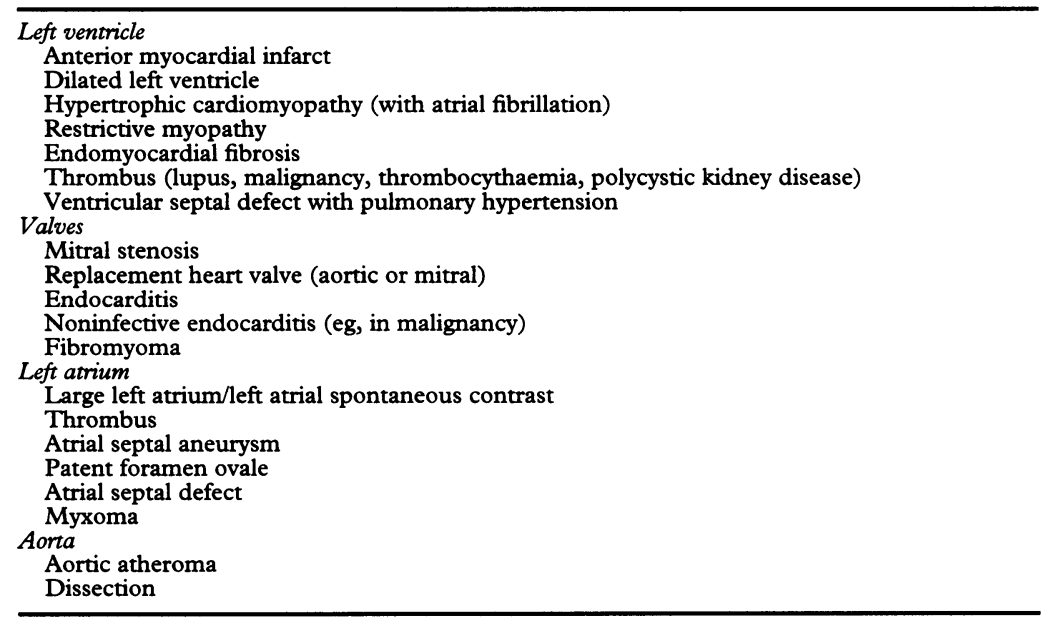

Table 5 Patent foramen ovale and stroke

\begin{tabular}{rlll}
\hline Reference & All infarcts & Crypotogenic & Control \\
\hline 4 & $13 \%$ & $15 \%$ & $23 \%$ \\
13 & $8 \%$ & - & - \\
14 & $13 \%$ & - & - \\
17 & $43 \%$ & $56 \%$ & $18 \%$ \\
18 & $31 \%$ & $44 \%$ & - \\
19 & $16 \%$ & $20 \%$ & $15 \%$ \\
20 & $16 \%$ & - & - \\
21 & $21 \%$ & $27 \%$ & - \\
\hline
\end{tabular}

25\%. Despite these methodological differences, a patent foramen ovale is generally found in around $20-30 \%$ of patients with cerebral infarction (table 5).

Cryptogenic strokes are cerebral infarcts with no obvious cause on ultrasound scanning of the carotid system or haematological analysis, and with no atrial fibrillation or other clinical evidence of heart disease. A small number of studies have shown a higher incidence of patent foramen ovale, up to $56 \%$, in cryptogenic than in total stroke. ${ }^{17}{ }^{19}$ However, other studies have failed to show an increased incidence. ${ }^{16}$ Furthermore, a similar figure $(23 \%)$ has been found in most control patients. ${ }^{41822}$

This similar incidence in patients with stroke and in control subjects has been interpreted to mean that patent foramen ovale is not a valid cause of stroke. ${ }^{18}$ The mechanism proposed certainly sounds intuitively unlikely. A venous embolism must be passing the region of the fossa ovalis at the precise time that right atrial pressure exceeds left atrial pressure sufficient for the foramen to open. The foramen must also be large enough to accommodate an embolic particle; the passage of a few microbubbles that are usually only $15-20 \mu \mathrm{m}$ in diameter ${ }^{23}{ }^{24}$ may not prove this. It is also thought that it is uncommon to find a source for venous emboli in patients with stroke and patent foramen ovale. ${ }^{25}$ However, this is an area of controversy because of the practical difficulty in venous imaging soon enough after admission because of stroke to detect primary rather than secondary thrombosis. One study found a deep vein thrombosis in 49 of 264 (19\%) patients after stroke compared with historically expected figures of $4-13 \% .{ }^{26}$ However, in this study venography was performed up to 90 days after the stroke and there were no control studies. Hanna et $a l^{23}$ found deep vein thrombosis in five of $16(31 \%)$ patients with patent foramen ovale alone (cryptogenic stroke), compared with only one of 23 patients $(4 \%)$ with patent foramen ovale and an additional cause for stroke, and only one of 35 patients $(3 \%)$ with a patent foramen ovale but no stroke. There is also anecdotal evidence that even large thrombi may catch in a patent foramen ${ }^{27}$ particularly in patients with raised right sided pressures as a result of pulmonary emboli. ${ }^{18}$ Thus, overall there is sufficient evidence to support the concept of patent foramen ovale as a cause of stroke, although as in other fields the echocardiographic abnormality cannot be interpreted outside the clinical context. If a patent foramen ovale is found in a patient with cryptogenic stroke, it is more likely to be significant than in a patient with another potential cause for stroke. 
Table 6 Left atrial spontaneous contrast and stroke

\begin{tabular}{llll}
\hline Reference & All stroke & Cryptogenic & Control \\
\hline 4 & $38 \%$ & $53 \%$ & $5 \%$ \\
13 & $18 \%$ & - & - \\
13 & $18 \%$ & - & - \\
14 & $26 \%$ & - & - \\
20 & $16 \%$ & - & - \\
21 & $19 \%$ & - & - \\
28 & $6 \%$ & - & - \\
\hline
\end{tabular}

Table 7 Left atrial thrombus and stroke

\begin{tabular}{lcll}
\hline Reference & All infarcts & Cryptogenic & Control \\
\hline 4 & $8 \%$ & - & $2 \%$ \\
13 & $10 \%$ & - & - \\
14 & $7 \%$ & - & - \\
18 & $5 \%$ & $8 \%$ & $2 \%$ \\
20 & $8 \%$ & - & - \\
28 & $4 \%$ & - & - \\
\hline
\end{tabular}

Table 8 Atrial septal aneurysm and stroke

\begin{tabular}{rlcll}
\hline Reference & Excursion & All infarcts & Cryptogenic & Control \\
\hline 4 & NS & $3 \%$ & $0 \%$ & $2 \%$ \\
14 & $15 \mathrm{~mm}$ & $1 \%$ & - & - \\
17 & $6 \mathrm{~mm}$ & $28 \%$ & - & $8 \%$ \\
18 & $11 \mathrm{~mm}$ & $8 \%$ & - & - \\
20 & $15 \mathrm{~mm}$ & $16 \%$ & - & - \\
22 & $15 \mathrm{~mm}$ & $5 \%$ & - & $4 \%$ \\
30 & $11 \mathrm{~mm}$ & $15 \%$ & - & $4 \%$ \\
\hline
\end{tabular}

NS, not stated.

Table 9 Aortic atheroma and stroke

\begin{tabular}{llll}
\hline Reference & All infarcts & Cryptogenic & Control \\
\hline 14 & $13 \%$ & - & - \\
22 & $22 \%$ & $4 \%$ & - \\
32 & $48 \%$ & - & $22 \%$ \\
\hline
\end{tabular}

\section{LEFT ATRIAL SPONTANEOUS CONTRAST AND} THROMBUS

Left atrial spontaneous contrast is shown in about $20 \%$ of patients after stroke compared with $5 \%$ of controls (table 6 ). ${ }^{4}$ Thrombus is found in $10 \%$ with stroke compared with $3 \%$ of controls (table 7) ${ }^{4}$ and may coexist with spontaneous contrast ${ }^{29}$ or may occur separately. As spontaneous contrast varies with gain settings and the carrying frequency of the probe, it is a relatively non-specific finding and future work must aim at grading the density of the effect.

\section{ATRIAL SEPTAL ANEURYSM}

Significant problems exist with the definition of atrial septal aneurysm. The threshold excursion ranges from as little as $6 \mathrm{~mm}^{17}$ to as much as $15 \mathrm{~mm},{ }^{18}{ }^{30}$ which must largely explain the wide variation in incidence between $1 \%^{14}$ and $28 \%$ (table 8). ${ }^{17}$ However, all studies ${ }^{131516}$ agree that approximately three quarters of aneurysms contain a patent foramen ovale. This is the most likely cause of stroke in such patients although there is rare anecdotal evidence of thrombus forming at the apex of an aneurysm.

\section{AORTIC ATHEROMA}

Again there are problems with definitions of aortic atheroma. Some authors report any degree of aortic atheroma ${ }^{31}$ giving an incidence after stroke of up to $33 \%$. Others use a threshold of $5 \mathrm{~mm}$, or report only complex, pedunculated or ulcerated atheroma, giving an incidence of $22 \% v 4 \%$ in controls (table 9 )..$^{22}$ There is good agreement that only large or complex atheroma constitute a significant risk of stroke with an adjusted relative risk of $7 \cdot 1$. This compares with a risk of 2.3 with simple atheroma and $2 \cdot 1$ with other intracardiac sources of emboli. ${ }^{22}$

Karalis et $a l^{33}$ found that embolic events occurred in $31 \%$ of patients with atheroma compared with only $4 \%$ in control subjects. Embolism was especially likely, in $73 \%$ of cases, when there was mobile atheroma protruding more than $5 \mathrm{~mm}$ into the lumen. This compared with an incidence of $12 \%$ in patients with simple atheroma. The risk of embolism was substantially increased with invasive interventions and occurred in four of 15 patients $(27 \%)$ with complex atheroma undergoing cardiac catheterisation or placement of aortic balloon pumps.

\section{CONTROVERSIAL CAUSES OF STROKE}

Some abnormalities may not genuinely be related to stroke. For example, although mitral prolapse has been reported in up to $40 \%$ of patients with ischaemic stroke, ${ }^{34}$ in most studies it is far less common and in some there were no cases at all. ${ }^{1}$ In the large SPAF study ${ }^{15}$ the incidence was $5 \%$, the same as in the control group. Furthermore the incidence of stroke in patients with mitral prolapse is low and can be accounted for by other associated factors such as atrial fibrillation. ${ }^{35} 36$

Mitral annular calcification may be related to stroke although the cause is not clear. In the Boston trial ${ }^{37}$ of warfarin in non-rheumatic atrial fibrillation, mitral annular calcification was present in $67 \%$ of patients with stroke compared with $29 \%$ without. A link between mitral annular calcification and aortic atheroma has been postulated although never tested, and at present we believe that there is insufficient evidence to assume that mitral annular calcification is an independent risk factor for stroke, nor is it clear how finding mitral annular calcification should alter management.

\section{Does transoesophageal echocardiography affect management?}

Many studies overemphasise the role of echocardiography in stroke by reporting even mild degrees of valve thickening or mitral prolapse leading to a rate of abnormality as high as $83 \% .^{4}$ Many of these patients have other causes of stroke such as atrial fibrillation or carotid atheroma, and a comprehensive assessment of the patient must be made rather than relying on the echocardiogram alone. Even then, about $30 \%$ of patients will have a potentially important abnormality on transoesophageal echocardiography.

Do these findings change management? In most cases where left atrial spontaneous contrast or thrombus are found the patient is in atrial fibrillation so will already have been anticoagulated with warfarin (in the absence of contraindications). If the risk of haemorrhage has been judged too high to start warfarin, the 
Table 10 Indications for echocardiography in patients with stroke or TLA

Transthoracic
As a prelude to transoesophageal examination in patients age $<50$ years
Significant clinical abnormality on auscultation, eg, mitral stenosis, atrial septal defect
Significant electrocardiographic abnormality, eg, anterior infarct, atrial fibrillation
Suspicion of endocarditis or myxoma, eg, high erythrocyte sedimentation rate
Transoesophageal
Suspicion of endocarditis or dissection and transthoracic echocardiography normal or views
suboptimal
Age under 50

Table 11 Recommendations for performing transoesophageal echocardiography

1. Look at left atrium and left atrial appendage for thrombus and spontaneous contrast

2. Check the atrial septum for myxoma, aneurysm (excursion $>15 \mathrm{~mm}$ ), and atrial septal defect using imaging and colour. If there is an aneurysm look for thrombus and spontaneous contrast

3. Perform a contrast study. Use $10 \mathrm{ml}$ dextrose saline or saline with $1 \mathrm{ml}$ air and $1 \mathrm{ml}$ of the patient's blood shot between two syringes using a three way tap and injected at speed on three occasions using different views of the atrial septal aneurysm. $\begin{array}{lll}\text { Grading of patent foramen ovale } & \text { small } & 1-5 \\ & \text { moderate } & 5-20 \\ & \text { large } & >20\end{array}$

4. Inspect the valves looking for vegetations or other masses, eg, fibromyoma

5. Inspect the left ventricle (although this will already have been assessed on transthoracic echocardiography)

6. Assess the aorta especially the arch looking for atheroma $>5 \mathrm{~mm}$ in depth or ulcerated or pedunculated atheroma can be associated with cerebral haemorrhage.

There is an argument for subjecting all patients to transoesophageal echocardiography if neurological and haematological investigations are unrewarding. The incidence of patent foramen ovale on transoesophageal examination is higher in the elderly than in the young. ${ }^{42}$ This is the reverse of the pattern seen at postmortem ${ }^{43}$ and may be explained by the fact that patent foramina in the elderly tend to be larger than in the young ${ }^{43}$ and therefore more readily detectable. The elderly are also more likely to have deep vein thrombosis or pulmonary hypertension. It is therefore possible that patent formen ovale is equally or more important in this age group. Transoesophageal echocardiography might be useful for stratifying risk to help decide who should have anticoagulation. However, no evidence exists to support this logical approach. We need a prospective study to see whether transoesophageal echocardiography can predict further events and whether a high risk group that will benefit from warfarin can be identified. Current recommendations for performing echocardiography are given in table 11 . ance of risk towards anticoagulation. The risk of recurrent stroke or TIA in patients with patent foramen ovale is not clear although preliminary work suggests that it is around $6.7 \%$ at two years with a trend towards fewer events in those anticoagulated with warfarin..$^{38}$ In patients with large defects admitting over 20 microcavitations, the risk of recurrent events may not be improved even with warfarin. ${ }^{39}$ These patients should perhaps be considered for closure of the defect. ${ }^{40}$

The finding of complex atheroma after stroke in patients about to undergo invasive procedures may lead to changes in management. For example, brachial rather than femoral angiography might be recommended or the site of bypass changed during coronary grafting.

Less frequently transoesophageal echocardiography has a major impact on management. For example, in patients with endocarditis, vegetations are detected with a sensitivity of approximately $90 \%$ compared with about $60 \%$ by transthoracic echocardiography, ${ }^{41}$ but on occasion the diagnosis may not have been considered clinically. Sometimes masses such as a myxoma or fibromyoma may be found, which were not detected on transthoracic echocardiography.

\section{When should we recommend echocardiography?}

Transthoracic echocardiography on its own is only clearly indicated in patients aged over 50 years where there is a relevant abnormality on clinical examination or the electrocardiogram. Transoesophageal echocardiography together with transthoracic examination is indicated in younger subjects to look for rare treatable causes such as myxoma or endocarditis, or the occasional thrombus found in the absence of atrial fibrillation or mitral stenosis (table 10). ${ }^{14}$ Computed tomography or magnetic resonance imaging must always be performed first as even atrial fibrillation or left atrial thrombus
1 Wolf PA, Dawber TR, Thomas JE, Kannel WB. Epidemiological assessment of chronic atrial fibrillation and the risk of stroke. Stroke 1978;28:973-7.

2 Ramirez-Lassepas M, Cipolle RJ, Bjork RJ. Can embolic stroke be recognised on the basis of neurological clinical criteria? Arch Neurol 1987;44:87-9.

3 Cerebral Embolism Task Force. Cardiogenic brain embolism: the second report of the Cerebral Embolism Task Force. Arch Neurol 1989;46:727-43.

4 Vandenbogaerde J, De Bleeker J, Decoo D, Cambier FB, Bergen J-M, Vandermersch $\mathrm{C}$, et al. Transoesophageal echo-Doppler in patients suspected of a cardiac source of peripheral emboli. Eur Heart $₹$ 1992;13:88-94.

5 Hart RG, Miller VT, Cerebral infarction in young adults: a practical approach. Stroke 1983;14:110-14.

6 Pruitt AA, Rubin RH, Karchmer AW, Duncan GW. Neurologic complications of bacterial endocarditis. Neurologic complications of bacte
Medicine (Baltimore) 1978;57:329-43.

7 Fuster V, Gersh BJ, Giuliani ER, Tajik AJ, Brandenberg RO, Frye RL. The natural history of idiopathic dilated cardiomyopathy. Am $\mathcal{F}$ Cardiol 1981;47:525-31.

8 Knopman DS, Anderson DC, Asinger RW, Greenland P, Mikell F, Good DC. Indications for echocardiography in patients with ischaemic stroke. Neurology 1982;32: 1005-11.

9 Bergerson G, Shah P. Echocardiography unwarranted in patients with cerebral ischaemic events. $N$ Engl $\mathcal{f} M e d$ 1981;304:489.

10 Burnett PJ. The role of echocardiography in the investigation of focal cerebral ischaemia. Postgrad Med $\mathcal{F} 1984 ; 60$. 116-19.

11 Shapiro LM, Westgaye CJ, Shine K, Donaldson R. Is cardiac ultrasound mandatory in patients with transient ischaemic attacks? BMF 1985;291:786-7.

12 Robbins JA, Sagar KB, French M, Smith PJ. Influence of echocardiography on management of patients with systemic emboli. Stroke 1983;14:546-9.

13 Lee RJ, Bartzokis T, Tiong-Keat Y, Grogin HR, Choi D, Schnittger I. Enhanced detection of intracardiac sources of cerebral emboli by transoesophageal echocardiograof cerebral emboli by tran
phy. Stroke 1991;22:734-9.

14 Leung DY, Black IW, Cranney G, Warren F, Walsh WF Grimm RA. Selection of patients for transoesophageal echocardiography after stroke and systemic embolic events. Stroke 1995;26:1820-4.

15 Stroke Prevention in Atrial Fibrillation Study Group Investigators. Predictors of thromboembolism in atria fibrillation. II. Echocardiographic features of patients a risk. Ann Intern Med 1992;116:6-12.

16 Sandercock P. Atrial fibrillation and stroke: prevalence in different types of stroke and influence on early and long term prognosis (Oxfordshire Community Stroke Project). BMF 1992;305:1460-5.

17 Cabanes L, Mas JL, Cohen A, Amarenco P, Cabanes PA Oubary P, Chedru F, et al. Atrial septal aneurysm and patent foramen ovale as risk factors for cryptogenic stroke in patients less than 55 years of age. Stroke 1993;24: 1865-72.

18 Homma S, Di Tullio MR, Sacco RL, Mihalatos D, Mandri $\mathrm{JL}$, Mohr JP. Characteristics of patent foramen ovale associated with cryptogenic stroke: a biplane transesophageal echocardiographic study. Stroke 1994;25: $582-6$.

19 Jones EF, Calafiore P, Donnan GA, Tonkin AM. Evidence 
that patent foramen ovale is not a risk factor for cerebral ischaemia in the elderly. Am $\mathcal{F}$ Cardiol 1994;74:596-9.

20 Pearson AC, Labovitz AJ, Tatineni S, Gomez CR. Superiority of transesophageal echocardiography in detecting cardiac source of embolism in patients with cerebral ischemia of uncertain etiology. $\mathcal{F}$ Am Coll Cardiol 1991;17:66-72.

21 de Belder MA, Lovat LB, Tourikis L, Leech G, Camm AJ. Limitations of transoesophageal echocardiography in patie

22 Jones EF, Kalman JM, Calafiore P, Tonkin AM, Donnan A. Proximal aortic atheroma-an independent risk factor for cerebral ischaemia. Stroke 1995;26:218-24.

23 Hanna JP, Jing Ping Sun, Furan AJ, Stewart WJ, Sila CA Ming Tan. Patent foramen ovale and brain infarctechocardiographic predictors, recurrence and prevention. echocardiographic predic
Stroke 1994;25:782-6.

24 Feinstein SB, Shah PM, Bing RJ, Meerbaum, Chang B-L Santillan G, et al. Microemboli visualized in the intact capillary circulation. Am $₹$ Cardiol 1984;4:595-60.

25 Ranoux D, Cohen A, Cabanes L, Amarenco P, Bousse MG, Mas JL. Patent foramen ovale: is stroke due to paradoxical embolism? Stroke 1993;24:31-4.

26 Stollberger C, Slany J, Schuster I, Leitner H, WaltherBenedikt W, Karnik R. The prevalence of deep venou thrombosis in patients with suspected paradoxical embolism. Ann Intern Med 1993;119:6461-5.

27 Prakash A, Chambers J, Holt P. Near miss paradoxical embolism. Br Heart f 1994;72:293.

28 Pop G, Sutherland GR, Koudstaal PJ, Sit TW, de Jong G Roelandt JRTC. Transesophageal echocardiography in the detection of intracardiac embolic sources in patients with transient ischaemic attacks. Stroke 1990;21:560-5.

29 Daniel WG, Nellessen U, Schroder E, Nonnast-Daniel B, Bednarski $P$, Nikatta $P$, et al. Left atrial spontaneous contrast in mitral valve disease: an indicator for an increased thromboembolic risk. $\mathcal{f} \mathrm{Am}$ Coll Cardiol 1988;11: 1204-11.

30 Pearson AC, Nagelhout D, Castello R, Gomez CR, Labovitz AJ. Atrial septal aneurysm and stroke: a transLabovitz A. Atrial septal aneurysm and stroke: a trans1991;18:1223-9.

31 Rauh G, Fischereder M, Spengel FA. Transesophageal echocardiography in patients with focal cerebral ischaemia of unknown cause. Stroke 1996;27:691-4.

32 Nihoyannopoulos P, Joshi J, Athanasopoulos G, Oakley CM. Detection of atherosclerotic lesions in the aorta by transesophageal echocardiography. Am $\mathcal{F}$ Cardiol 1993 71:1208-12.

33 Karalis DG, Chandrasekaran K, Victor MF, Ross J, Mint GS. Recognition and embolic potential of intraaortic atherosclerotic debris. $\mathcal{F}$ Am Coll Cardiol 1991;17:73-8.

34 Barnett HJM, Boughner DR, Taylor DW, Cooper PE Kostuk WJ, Nichol PM. Further evidence relating mitra valve prolapse to cerebral ischaemic events. $N$ Engl f Med 1980;307:369-70.

35 Mills Prose J, Hollingsworth J, Amara I, Craige E. Long term prognosis of

36 Nishimura RA, McGoon M, Shub C, Miller FA, Ilstrup DM, Tajik AJ. Echocardiographically documented mitral valve prolapse. Long-term follow-up of 237 patients. $N$ valve prolapse. Long-term fo

37 Boston Area Anticoagulation Trial for Atrial Fibrillation investigators. The effect of low dose warfarin on the risk of investigators. The effect of low dose warfarin on the risk of Engl f Med 1990;323:1505-11.

38 Mas J-L, Zuber M. Recurrent cerebrovascular events in patients with patent foramen ovale, atrial septal aneurysm or both and cryptogenic stroke or transien ischaemic attack. Am Heart $¥$ 1995;130:1083-8.

39 Stone DA, Godard J, Corretti MC, Kittner SJ, Sample C, Price TR, et al. Patent foramen ovale: association between the degree of shunt by contrast transesophageal echocardiography and the risk of future ischemic neurologic events. Am Heart f 1996;131:158-61.

40 Wilmshurst PT, de Belder MA. Patent foramen ovale in adult life. Br Heart f 1994;71:209-12.

41 Taams MA, Gussenhoven EJ, Bos E, de Jaegere P, Roelend JRTC, Sutherland GR, et al. Enhanced morphologic diag nosis in infective endocarditis by transoesophagea echocardiography. Br Heart $\mathcal{1}$ 1990;63:109-13.

42 de Belder MA, Tourikis L, Leech G, Camm J. Risk of patent foramen ovale for thromboembolic events in all age groups. Am F Cardiol 1992;69:1316-20.

43 Hagen PT, Scholz DG, Edwards WD. Incidence and size of patent foramen ovale during the first 10 decades of life: of patent foramen ovale during the first 10 decades of life: 1984;59:17-20. 